\title{
Image search triggers Italian police probe
}

Method for checking global literature leads to investigation of cancer researcher.

\section{BY ALISON ABBOTT}

A s the editor-in-chief of two journals, cell biologist Gerry Melino is used to having an inbox full of concerns, of varying levels of seriousness, about data in published papers. But an e-mail he received criticizing a 2006 paper in one of his journals, Cell Death and Differentiation, surprised him with its unusual professionalism and precision. He fast-tracked an independent investigation into the paper - and this week the journal will publish a retraction by the authors, led by prominent Italian cancer researcher Alfredo Fusco. The paper had been found to contain "inappropriately duplicated" images.

The e-mail criticizing Fusco's paper was sent in August by Enrico Bucci, who runs a small biomedical start-up company in northern Italy offering publication of meta-analysis services. He had detected the gel anomalies while conducting a global search to exclude contaminated literature from his database. The search has revealed anomalous images in around one-quarter of biomedical papers examined so far.

Fusco, a professor at the University of Naples and an associate member of the Accademia dei Lincei, Italy's prestigious national academy, is now under investigation by the police and by his university.

Although Fusco is the first person to be investigated as a result of Bucci's work, other scientists may now find their work under scrutiny. The affair has also revealed the absence of a system for investigating allegations of misconduct in Italy's universities.

The story began in 2008, when Bucci, a molecular biologist, founded BioDigitalValley in Pont Saint Martin, Italy. Its services include pulling out all published images of gelelectrophoresis analysis - which separates and identifies large molecules such as proteins and sequences of RNA - that are relevant to a particular disease or tissue.

Bucci and his team created a database hosting all accessible biomedical papers published since 2000. But cleaning it of scientific contamination was not the quick job he had imagined. First he removed retracted papers; then he created a network of scientists who had been co-authors at least three times

with authors of the retractions.

The list ran to more than one million, so he looked only at Italian scientists. Using inhouse software that could isolate images of, for example, gels, and check them for simple features such as possibly duplicated portions, he ran an automatic check of all the papers the Italian researchers had published. He focused on highly cited researchers for whom the

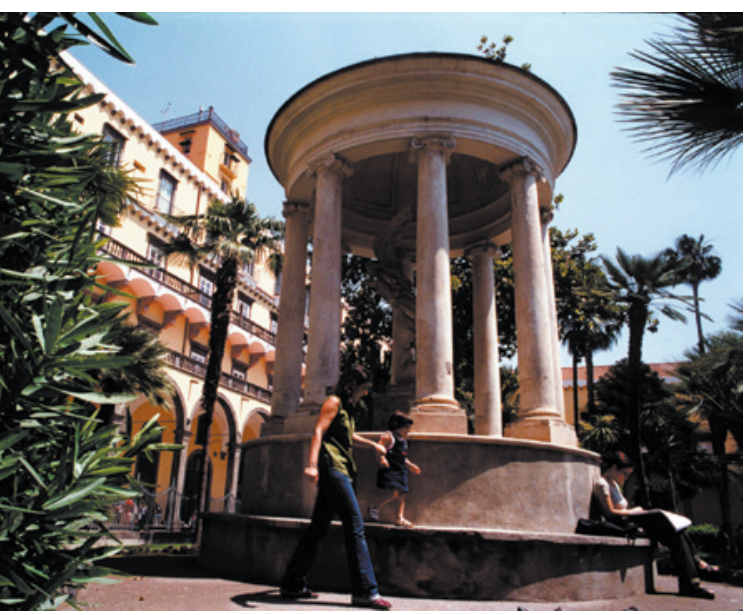

The University of Naples is carrying out an internal inquiry following allegations against one of its researchers.

automatic check had revealed multiple papers with anomalous images. Fusco, a specialist in cancer genetics, topped the list with eight papers.

Bucci's team then checked all of Fusco's research papers in greater detail using gelchecking software to identify various features, such as reused gel images or markings that suggested cut-and-pasted images. Out of around 300 papers on which Fusco was first or last author, the team found 53 containing gels with potential irregularities, including one from as far back as 1985 .

After discovering that there was no academic organization in Italy that dealt with such findings, in February 2012 Bucci contacted the Milan police.

He says that his team is now working on tens of other cases of Italian scientists who scored highly in his automated check and collaboration network. "The value of my method, with its scientists' network element, is that the first quick check allows you to decide which authors to spend detailed time on," says Bucci.

Now midway through the analysis, he estimates that around one-quarter of the thousands of papers featuring gels that he has analysed so far potentially breached widely accepted guidelines on reproducing gel images. And around $10 \%$ seem to include very obvious breaches, such as cutting and pasting of gel bands. Some journals were more affected than others, he says. Those with a high impact factor tended to be slightly less affected. He plans to publish his results.

The public prosecutors must decide by April whether to bring charges against Fusco. A source close to the police investigation confirms that around 60 papers by Fusco are being studied, including a 2007 paper in the Journal of Clinical Investigation that was retracted by the editors in November. In an e-mail to Nature, Fusco declined to comment until the investigations are complete.

When details of the inquiry were leaked to an Italian newspaper in October, the rector of Fusco's university set up a three-man internal committee headed by Roberto Di Lauro, vice-rector for research at the University of Naples, that is expected to report by the end of the year. Di Lauro has co-authored nine papers with Fusco, but says that he will resign from the committee if any of these papers feature in the investigation.

Because universities in Italy have no established guidelines for handling such allegations, the committee is working out its operating procedures as it goes along, says Di Lauro. "We are taking the opportunity to make a report to our rectors on how universities should handle such cases," he adds.

Such a report would be welcomed. "Italy is far behind other European countries in this," says Nicole Föger of the Austrian Agency for Research Integrity in Vienna, and chair of the European Network of Research Integrity Offices. "But we have noticed that a country can catch up quickly after a scandal."

"We editors are bombarded by low-quality allegations to the point that we can't cope," says Melino, who has joint appointments at the MRC Toxicology Unit at the University of Leicester, UK, and the University of Rome Tor Vergata. "But Bucci's systematic approach to addressing the genuine problem of literature contamination is actually very helpful." - 